\title{
A Study on the Contact Force between Catenary and Pantograph in Duplicate KTX-II Operation
}

\author{
Seung-Wook Kang*广, Sang-Ahm Kim* and In-Chol Kim*
}

\begin{abstract}
Electric railway system driving the electric cars using power from catenary has been secured by performance of stable tracking between pantograph and catenary. The performance of the power collecting of pantograph is the one of the most important skills for high-speed train speed. The first Korea high-speed train(KTX) is 20 cars in one train set. In the meantime, collecting capability of single pantograph collector at one train set was confirmed through evaluation of the performance and the stability test. However, more research is needed to build for a stable collecting capability of coupled Korea's KTX-II High-speed system which is developed in Korea. In this study, actual vehicle test of coupled KTXSanchon was made to analyzing the data presented by the dynamic nature of catenary and pantograph, and the interface characteristics.
\end{abstract}

Keywords :Catenary, Pantograph, Contact force, KTX-Sancheon.

\section{Introduction}

Opening of the High Speed Rail (KTX) in 2004 can be called a new chapter that transforms Korea railroad history as a transportation revolution after laying of GyeongIn railway line opened in 1899.

Korea railroad speed was stuck at $100 \mathrm{~km} / \mathrm{h}$ more than 100 years. After transformation of the $300 \mathrm{~km} / \mathrm{h}$ speed truly has turned the pattern of our daily lives as well as the social paradigm that can not be done without a KTX.

Measuring catenary uplift and contact force should be completed within a very short period of time during pantograph operation. For this reason, such a measurement requires a system with fast response speed, few errors and flexibility to variation in location. Uplift and contact force require diverse measurement technologies and standards for themselves in line with increasing railroad electrification and growing train speed. This research measured catenary uplift and contact force accompanied by the elevated speed of KTX-II, etc. and analyzed the outcome.

\footnotetext{
Corresponding author: Catholic Sangji College, Korea E-mail : ksw0413@csj.ac.kr
}

\section{Main Points}

\subsection{Technological characteristics of high- speed-train power collector}

Korea's metropolitan area subway receives power from 6 to 10 sets of power collectors through catenary contact. As for high-speed trains such as KTX-I, they gain power from 1 power collector among a set of two collectors and KTXII duplicate operation is powered by contacting to catenary 2 sets of power collectors among 4 sets. Therefore, the interface between high-speed train's pantograph and catenary is essential technology for the entire driving quality of a train and its highest speed evaluation. As for KTXII duplicate operation, in particular, each system should be individually powered and its pantograph is initialled separately as well. During high-speed train operation, front-
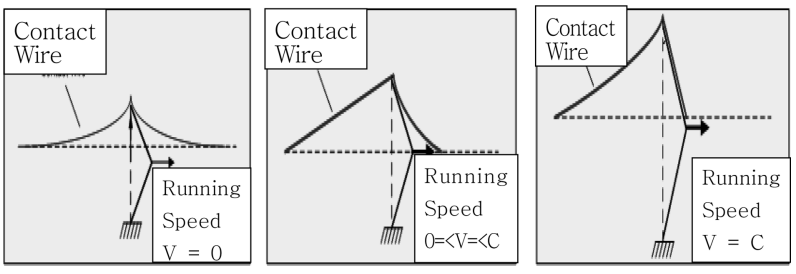

Fig. 1 Correlation between wave speed \& catenary 


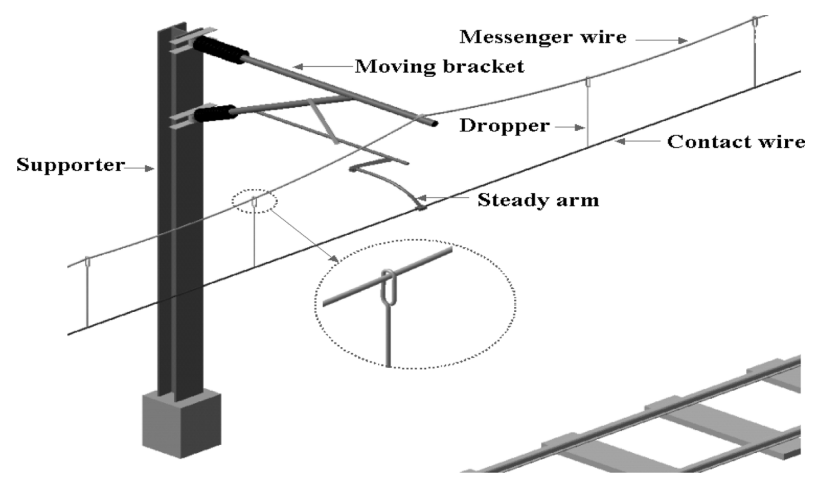

Fig. 2 KTX catenary system

pantograph-generated waves heavily affect rear pantograph operation. As such, catenary-pantograph interface grows more significant for duplicate operation.

EN50119 rule also sets high-speed train's driving speed at $70 \%$ or less than the speed of wave as shown in Fig. 1 for stable pantograph power collection.

There are two different methods of evaluation the power collection quality - EN and UIC - and only one of the two should be applied. One measured contact force between catenary and pantograph and regards the collection quality as good if $F_{\text {mean }}-3 \sigma$ value - the difference between average contact force and the triplication of standard deviation - exceeds a certain threshold. The other method involves electric arc. This method is used when contact force is hard to measure. It assesses if the ratio between arc's accumulated hours and collecting hours, when the arc lasted at least $10 \mathrm{~ms}$, is less than $1 \%$. Users may chose either of them depending on the type of a catenary system.

South Korea's high-speed-train catenary system, as displayed in Fig. 2, is consisted of contact wire that supplies power, messenger wire that supports load, dropper, bracket, stead arm that mitigates and control shocks during train operation, electric pole, etc.

\subsection{Equation for pantograph contact force measurement}

When pantograph is driving while collecting power, contact force $\mathrm{F}_{c}$ established equilibrium with shear forces and inertial forces on the suspension of a collector plate and aerodynamic forces on the collector plate. In Fig. 3 above, contact force $\mathrm{F}_{c}$ maintains force equilibrium with shear forces and inertial forces on the collector plate's suspension and aerodynamic force on it. Thus, force equilibrium equation is gained as follows:

$$
\mathrm{F}_{L}+\mathrm{F}_{R}-\sum \mathrm{m}_{i} a_{i}=\mathrm{F}_{c}-\mathrm{F}_{\text {aero }}
$$

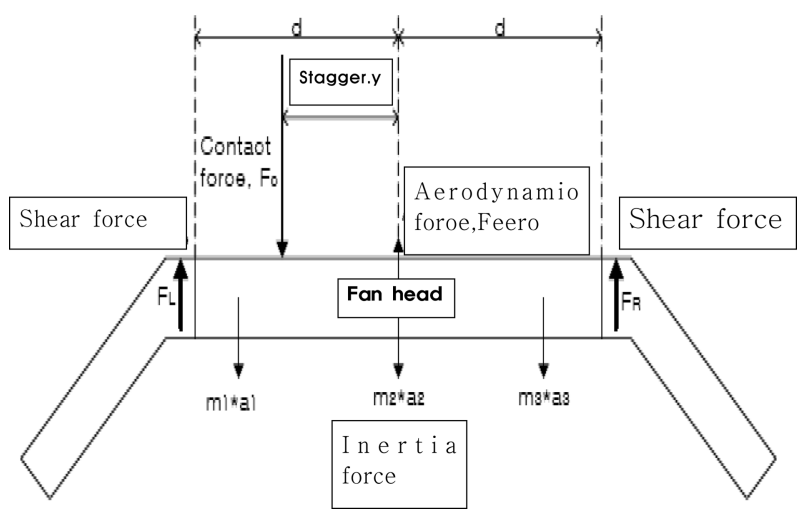

Fig. 3 pantograph contact force

Here, shear forces $\mathrm{F}_{R}, \mathrm{~F}_{L}$ is obtained by using a strain gage. and equivalent masses $\mathrm{m}_{1}, \mathrm{~m}_{2}, \mathrm{~m}_{3}$ are calculated based on the dynamic characteristics test of pantograph. $a_{1}$ is acceleration and collector plate aerodynamic force $\mathrm{F}_{\text {aero }}$ is measured in advance through aerodynamic test with an attached accelerometer since the bending resonance mode exists in the frequency.

The force equilibrium between catenary and pantograph can also be described in the following equations (1) and (2). Contact force applied to pantograph and catenary can be estimated by using aerodynamic force obtained based on left/right shear forces as well as aerodynamic force test. The equation is as follows:

$$
F_{i}=-F_{c}+F_{a}+F_{s}
$$

Here, $\mathrm{F}_{i}$ : inertial forces[N], $\mathrm{F}_{c}$ : contact force $[\mathrm{N}]$ $\mathrm{F}_{a}:$ aerodynamic force $[\mathrm{N}], F_{s}$ : lifting force $[\mathrm{N}]$

From the equation above, the average value of inertial forces converge to " 0 " as upward/downward forces appear from the equilibrium point depending on the acceleration movement of pantograph collector plate. Therefore, it can be expressed as the equation (2) below:

$$
F_{c(\text { mean })}=F_{a}+F_{s}
$$

In the equations (1) and (2), aerodynamic force $\mathrm{Fa}$ is related to train speed and high-speed train's aerodynamic force can be obtained via high-speed driving test and experimental relation expression to be shown in the equation (3) below:

$$
F_{a}=K_{a} \times\left(\frac{V}{200}\right)^{2}
$$

Here, $\mathrm{V}:$ train speed $[\mathrm{km} / \mathrm{h}]$

$\mathrm{K}_{a}$ : aerodynamic constant $\left.(\mathrm{N} /(\mathrm{km} / \mathrm{h}))^{2}\right]$

$\mathrm{F}_{a}:$ aerodynamic force $[\mathrm{N}]$ 


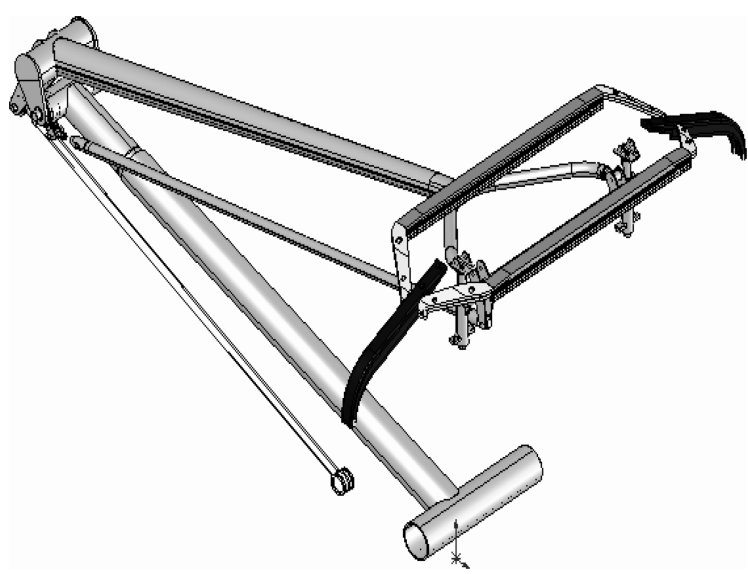

Fig. 4 KTX-II(Sancheon) pantograph

\subsection{KTX-II pantograph technological review}

KTX-II (Sancheon) pantograph, unlike KTX-I, is designed as a separated type, not an integrated type as in Fig. 4 for efficient catenary contact.

$\mathrm{F}_{c}$, power generated by the contact of pantograph Contact Strip and catenary, can be largely divided into aerodynamic force $\left(\mathrm{F}_{\text {aero }}\right)$ applied to static lifting force $\left(\mathrm{P}_{a}\right)$ and pantograph as a whole; and inertial forces $\left(\mathrm{F}_{\text {inf }}\right)$ by acceleration.

That is, $\mathrm{F}_{c}=\mathrm{F}_{\text {aero }}+\mathrm{F}_{\text {inf }}$.

Here $\mathrm{F}_{\text {aero }}$ is applied to the entire pantograph and can be divided into aerodynamic force $\left(\mathrm{F}_{s p}\right)$ working on Collector Head and aerodynamic force $\left(\mathrm{F}_{n s p}\right)$ for others.

Therefore, $\mathrm{F}_{c}=\mathrm{P}_{a}+\mathrm{F}_{\text {areo }}+\mathrm{F}_{\text {inf }}=\mathrm{P}_{a}+\mathrm{F}_{s p}+\mathrm{F}_{n s p}+\mathrm{F}_{\text {inf }}$ and here, Suspension's Spring Force $\left(\mathrm{F}_{\text {sus }}\right)$ equals to the sum of $\mathrm{P}_{a}$ and $\mathrm{F}_{\text {sus }}$.

That is, $\mathrm{F}_{\text {sus }}=\mathrm{P}_{a}+\mathrm{F}_{n s p}$. Thus, the entire contact force can be expressed as follows:

$$
\begin{aligned}
& \mathrm{F}_{c}=\mathrm{F}_{s u s}+\mathrm{F}_{i n f}+\mathrm{F}_{s p} \\
& \mathrm{~F}_{s p}=\mathrm{F}_{c}-\mathrm{F}_{i n f}-\mathrm{F}_{s u s}
\end{aligned}
$$

$\mathrm{F}_{s p}$ can be theoretically expressed as being proportional to the square of the speed based on aerodynamic characteristics as follows:

$$
\mathrm{F}_{s p}=\mathrm{A}+\mathrm{B}_{u}^{2}
$$

Here, A is a constant made by offsetting measurement errors and environment conditions between measurement systems. B refers to aerodynamic force coefficient and $\mathrm{v}$ is speed.

Aerodynamic test was performed by setting static lifting force at $90 \mathrm{~N}$, Air Spoiler angle at 20 degrees, Air Foil angle at 0 degree, and basic test speed at $300 \mathrm{~km} / \mathrm{h}$.

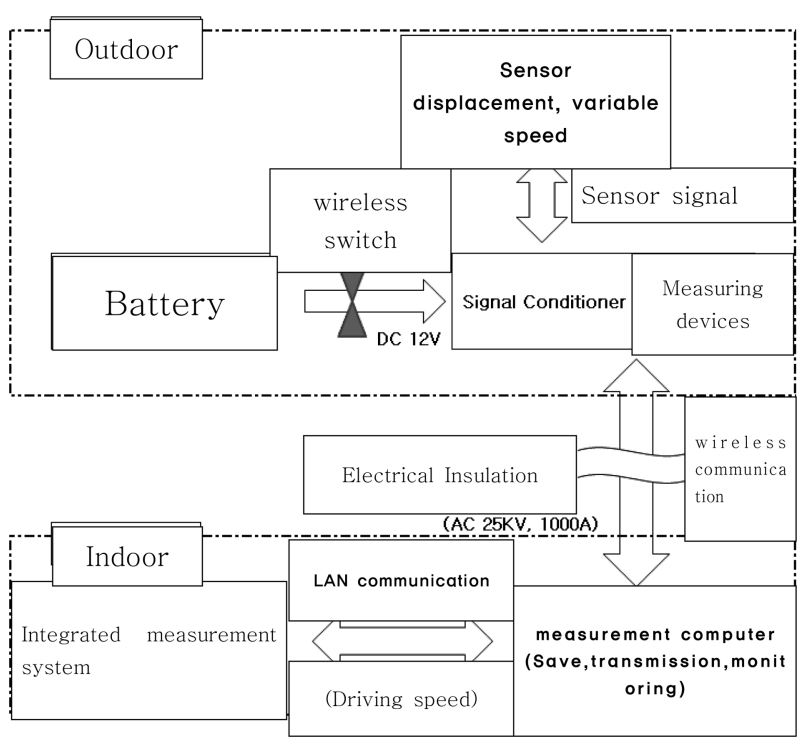

Fig. 5 Measuring equipment configuration

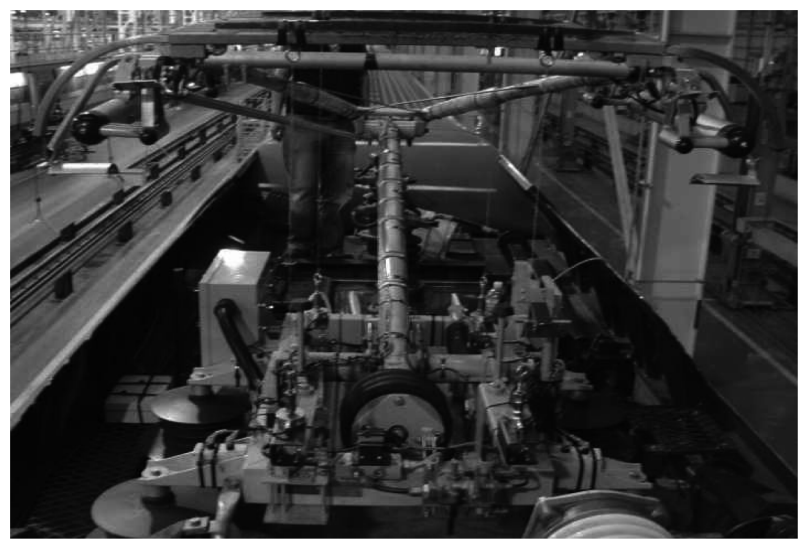

Fig. 6 Measuring equipment installation pantograph

Fig. 5 is about measurement equipment configuration.

\section{Outdoors}

sensor (displacement, variable velocity)

battery wireless switch sensor signal measuring equipment wireless LAN communication

electrical insulation

Indoors

integrated measuring system

LAN communication

measurement data (driving speed)

measuring computer (data saving, sending, monitoring)

Measuring equipments were installed as in Fig. 6. Four Load Cells were fixed on Base Frame. $F_{c}$ is the sum of forces measured in the 4 Load Cells.

Fig. 7 aerodynamic force characteristics on the pantograph 


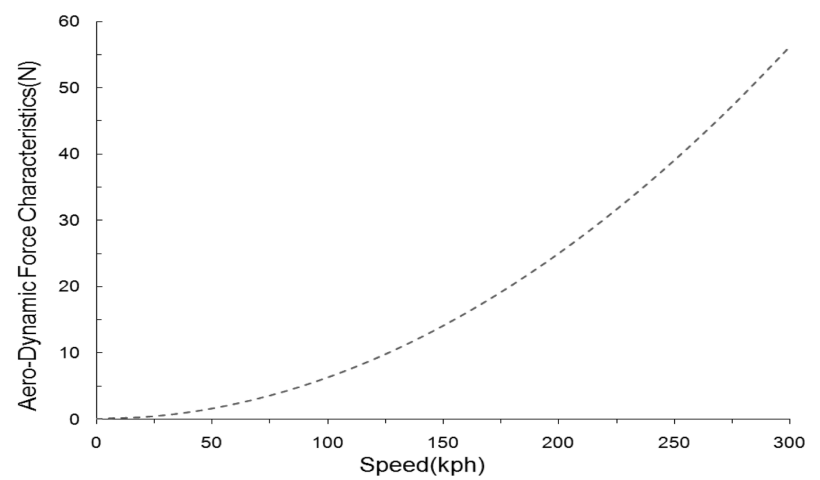

Fig. 7 Displays the relationship between speed and aerodynamic characteristics.

Table 1. Evaluation Threshold

\begin{tabular}{cc}
\hline item & threshold \\
average contact force & average contact force $\left(\mathrm{F}_{\text {mean }} \leq 200 \mathrm{~N}\right.$ \\
loss of contact rate & loss of contact rate: $\mathrm{F}_{\text {mean }}-3 \sigma \geq 0$ \\
\hline
\end{tabular}

Table 2 Loss of Contact Rate and Contact Force Threshold

\begin{tabular}{|c|c|c|c|}
\hline item & $\mathrm{AC} 1$ & $\mathrm{AC} 3$ & $\mathrm{AC} 4$ \\
\hline $\begin{array}{c}\text { catenary wave speed } \\
\qquad v(\mathrm{~km} / \mathrm{h})\end{array}$ & $v \leq 160$ & $160<v \leq 220220<v<250$ & $v \geq 250$ \\
\hline $\begin{array}{l}\text { average contact } \\
\text { force } \mathrm{F}_{m}(\mathrm{~N})\end{array}$ & \multicolumn{3}{|c|}{$\begin{array}{l}\text { not exceeding } 200 \mathrm{~N} \text { below the limit set } \\
\text { according to speed }\end{array}$} \\
\hline $\begin{array}{l}\text { statistical minimum } \\
\text { contact force at the } \\
\text { highest speed }\end{array}$ & & $\mathrm{F}_{m}-3 \sigma$ & \\
\hline $\begin{array}{l}\text { loss of contact rate } \\
\text { at the highest speed } \\
\qquad(\%)\end{array}$ & 1 & 1 & 1 \\
\hline $\begin{array}{l}\text { minimum duration } \\
\text { of arc under } \\
\text { consideration }(\mathrm{ms})\end{array}$ & 10 & 10 & 10 \\
\hline $\begin{array}{l}\text { maximum duration } \\
\text { allowed (ms) }\end{array}$ & 25 & 25 & 25 \\
\hline
\end{tabular}

\subsection{Pantograph contact force evaluation threshold}

In this thesis, in line with the UIC standard, de-wiring from the contact wire and contact force were examined to test pantograph performance in KTX-II (Sancheon) duplicate operation. Contact force, here, refers to the contact force between collector plate and catenary. As in Fig. 8, average contact force is the average value of the contact force between pantograph and catenary. De-wiring rate is minimum statistics contact force gained by subtracting the triplicated average deviation value from average contact force.

EN50119:2001 regulates contact forces as in Fig. 9.

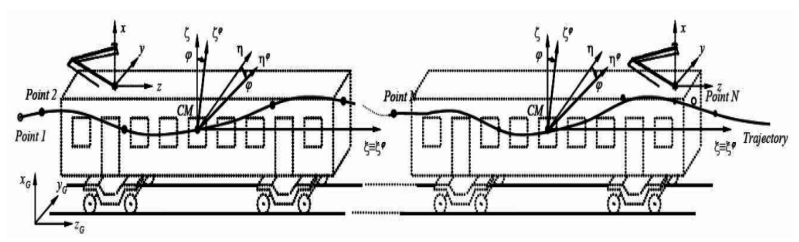

Fig. 8 Dynamics between front and rear pantograph in duplicate operation

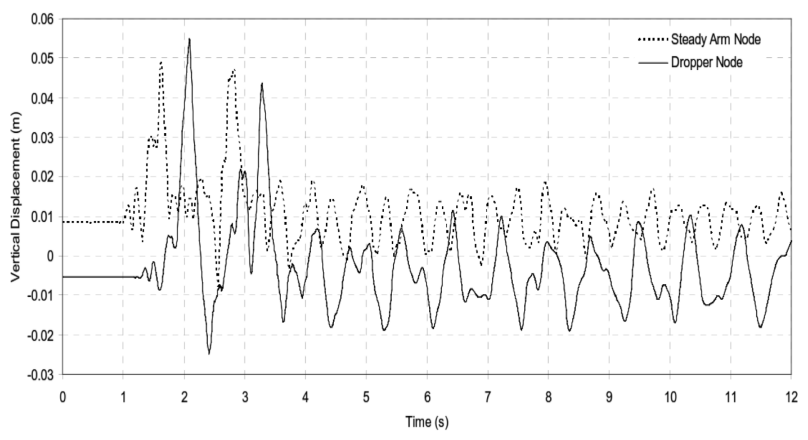

Fig. 9 Displacement of fittings at $300 \mathrm{~km} / \mathrm{h}$

\subsection{KTX-II(Sancheon) duplicate operation's pantograph contact force test methodology}

(1) Set intervals

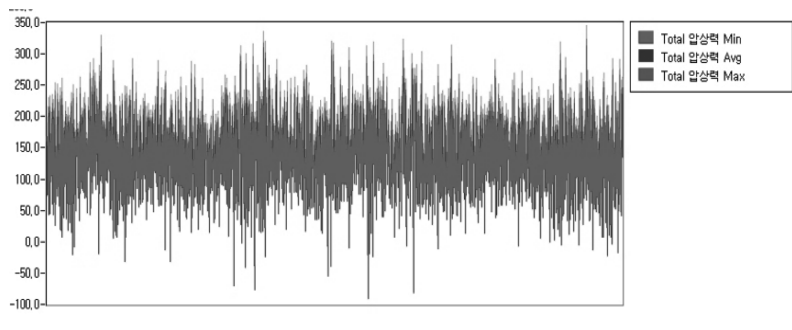

(2) Get average of data in each interval: $\mathrm{F}_{\text {mean }}=\frac{\sum_{i=1}^{n}}{n} \mathrm{~F}_{i}$,

Here, measure $\mathrm{F}_{i}$ for the ith time. $\mathrm{n}$ represents the total data number.

(3) Calculate standard deviation of data in each interval:

$3 \sigma=3 \sqrt{\frac{\sum_{i=1}^{n}\left(F_{\text {mean }}-F_{i}\right)^{2}}{n}}$

(4) Calculate $\mathrm{F}_{\text {mean }}-3 \sigma$

(5) Calculate the range of Air Spoiler aerodynamic force characteristics at $300 \mathrm{~km} / \mathrm{h}$.

(6) Re-calculate $\mathrm{F}_{\text {mean }}$ outcome in consideration of Air Spoiler aerodynamic force characteristics and spring hysteresis at the set speed.

(7) Test Method : Measured equipment installation on pantograph 


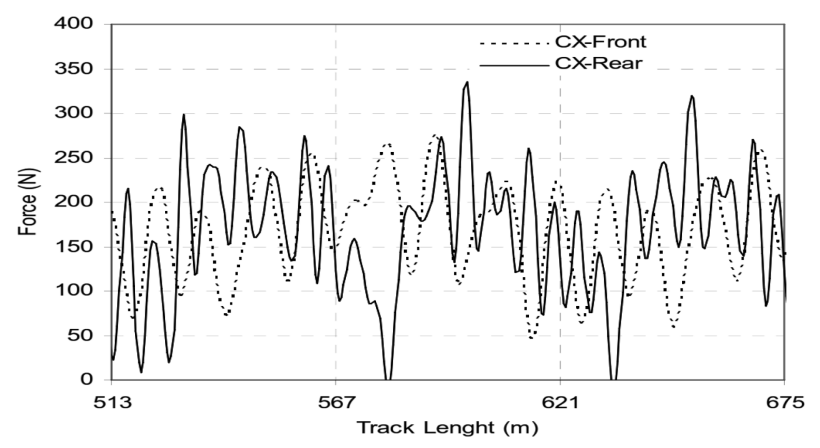

Fig. 10 Forces applied to front/rear pantograph

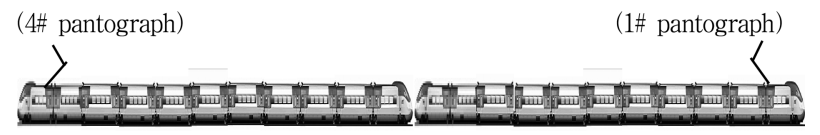

Fig. 11 KTX-Sancheon duplicate operation pantograph location (driving direction $\Rightarrow$ )

\section{$2.6 \mathrm{KTX}-\mathrm{II}($ Sancheon) duplicate pantograph contact force test}

For high-speed train's duplicate operation, its front/rear pantograph contact force is closely related to its speed and the related waves also deliver significant vibration and forces to dropper and fittings. Recognizing such an aspect, the researchers, for the study, have performed a test by increasing speed in phase.

Fig. 10 shows dynamics caused by pantograph contact during train duplicate operation.

At a driving speed of $300 \mathrm{~km} / \mathrm{h}$, the displacement of the steady arm and dropper caused by the pantograph contact force is expressed in Fig. 11.

As the Figure above shows, at the speed of $300 \mathrm{~km} / \mathrm{h}$, displacement according to pantograph contact swings greatly for approximately 2 seconds and $166 \mathrm{~m}$, distance for the 2 seconds after pantograph slide, causes significant vibration and impacts to rear pantograph. After the 2 seconds, displacement is reduced sharply as supports absorb vibration.

Fig. 12 shows the difference of forces working on front/rear pantographs (set every $200 \mathrm{~m}$ ) in duplicate operation.

In KTX-II (Sancheon) duplicate operation test drivings started from June 2010, the researchers elevated speed in a phased manner to measure pantograph contact force. This study examined pantographs \#1 and \#4 to analyze contact forces at speed of $250 \mathrm{~km} / \mathrm{h} \sim 300 \mathrm{~km} / \mathrm{h}$.

(1\# Panto and 4\# Panto are $362 \mathrm{~m}$ away from each other).

Fig. 13 is about the location of pantographs \#1 and 4 in their duplicate operation.

The section examined in the experiment is between
Gwangmyeong Seodaejeon Dongdaegu. For this study, we operated round trip from Seoul Station to Dajeon and Dongdaegu after service hour.

(1) pantograph contact forces at the average speed of $248 \mathrm{~km} / \mathrm{h}$

Table 3 Contact Force at the Speed of $248 \mathrm{~km} / \mathrm{h}$

\begin{tabular}{|c|c|c|c|}
\hline $\begin{array}{c}\text { subject of } \\
\text { measurement }\end{array}$ & outcome & threshold & note \\
\hline $\begin{array}{l}\text { average lifting } \\
\text { force }\left(\mathrm{F}_{\text {mean }}\right)\end{array}$ & 158 & 200 or under & \multirow{5}{*}{$\begin{array}{c}\text {-average speed: } \\
248 \mathrm{kph} \\
\text {-static lifting } \\
\text { force: } 90 / 90 \mathrm{~N}\end{array}$} \\
\hline $\begin{array}{c}\text { lifting force standard } \\
\text { deviation }(\sigma)\end{array}$ & 43 & & \\
\hline $\mathrm{F}_{\text {mean }}-3 \sigma$ & 29 & 0 or over & \\
\hline $\mathrm{F}_{\text {mean }}+3 \sigma$ & 288 & 350 or under & \\
\hline conclusion & appropriate & & \\
\hline
\end{tabular}

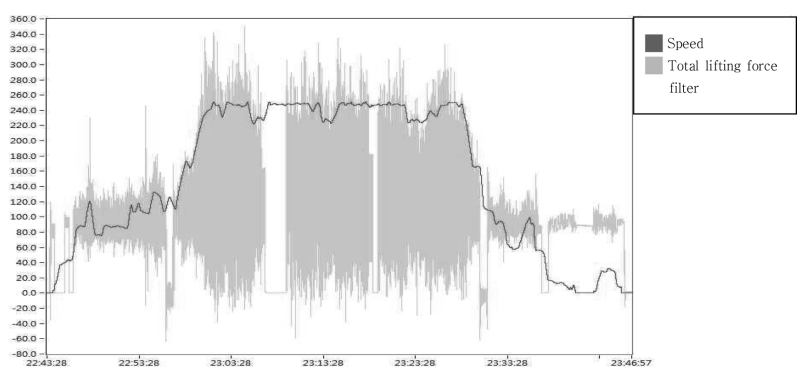

Fig. 12 Test data

(2) pantograph contact force at the average speed of $269 \mathrm{~km} / \mathrm{h}$

Table 4 Contact Force at the Speed of $269 \mathrm{~km} / \mathrm{h}$

\begin{tabular}{|c|c|c|c|}
\hline $\begin{array}{c}\text { subject of } \\
\text { measurement }\end{array}$ & outcome & threshold & \multirow{6}{*}{$\begin{array}{c}\text {-average speed: } \\
269 \mathrm{kph} \\
\text {-static lifting } \\
\text { force: } 90 / 90 \mathrm{~N}\end{array}$} \\
\hline $\begin{array}{l}\text { average lifting } \\
\text { force }\left(\mathrm{F}_{\text {mean }}\right)\end{array}$ & 170 & 200 or under & \\
\hline $\begin{array}{c}\text { lifting force standard } \\
\text { deviation }(\sigma)\end{array}$ & 48 & & \\
\hline $\mathrm{F}_{\text {mean }}-3 \sigma$ & 26 & 0 이상 & \\
\hline $\mathrm{F}_{\text {mean }}+3 \sigma$ & 314 & 350 이하 & \\
\hline conclusion & appropriate & & \\
\hline
\end{tabular}

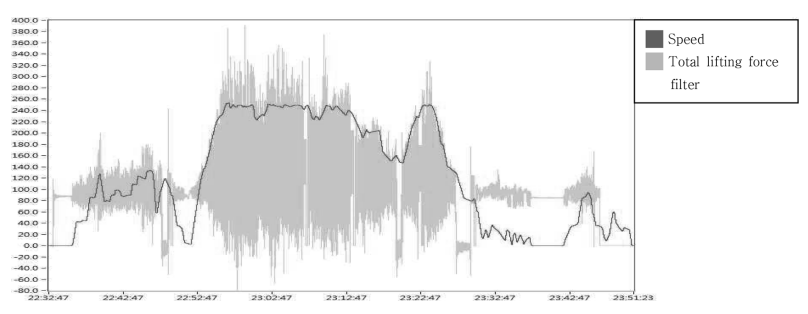

Fig. 13 Test data 
(3) pantograph contact force at the average speed of $284 \mathrm{~km} / \mathrm{h}$

Table 5 Contact Force at the Speed of $284 \mathrm{~km} / \mathrm{h}$

\begin{tabular}{cccc}
\hline $\begin{array}{c}\text { subject of } \\
\text { measurement }\end{array}$ & outcome & threshold & note \\
\cline { 1 - 2 } $\begin{array}{c}\text { average lifting } \\
\text { force }\left(\mathrm{F}_{\text {mean }}\right)\end{array}$ & 178 & 200 or under & \\
$\begin{array}{ccc}\text { lifting force standard } \\
\text { deviation }(\sigma)\end{array}$ & 55 & 0 or over & $\begin{array}{c}\text { speed:284 kph } \\
\text {-static lifting } \\
\text { force:90/90N }\end{array}$ \\
\cline { 1 - 2 } $\mathrm{F}_{\text {mean }}-3 \sigma$ & 13 & 350 or under & \\
\cline { 1 - 2 } $\mathrm{F}_{\text {mean }}+3 \sigma$ & 343 & \\
\cline { 1 - 2 } conclusion & appropriate & \\
\cline { 1 - 2 } & \multicolumn{1}{c}{} &
\end{tabular}

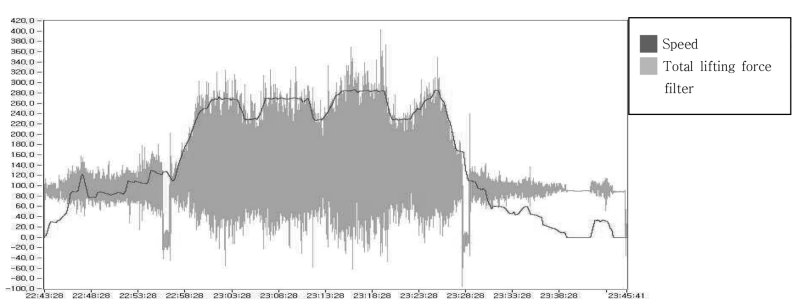

Fig. 14 Test data

(4) pantograph contact force at the speed of $301 \mathrm{~km} / \mathrm{h}$

Table 6 Contact Force at the Speed of $301 \mathrm{~km} / \mathrm{h}$

\begin{tabular}{cccc}
\hline $\begin{array}{c}\text { subject of } \\
\text { measurement }\end{array}$ & outcome & threshold & note \\
\cline { 1 - 3 } $\begin{array}{c}\text { average lifting } \\
\text { force }\left(\mathrm{F}_{\text {mean }}\right)\end{array}$ & 174 & 200 or under & \\
$\begin{array}{ccc}\text { lifting force standard } \\
\text { deviation }(\sigma)\end{array}$ & 57 & 0 or over & $\begin{array}{c}\text {-average speed: } \\
\text { 301kph } \\
\text {-static lifting } \\
\text { force:90/90N }\end{array}$ \\
\cline { 1 - 2 } $\mathrm{F}_{\text {mean }}-3 \sigma$ & 3 & 350 or under & \\
\cline { 1 - 2 } $\mathrm{F}_{\text {mean }}+3 \sigma$ & 345 & & \\
\cline { 1 - 2 } conclusion & appropriate & \\
\cline { 1 - 2 }
\end{tabular}

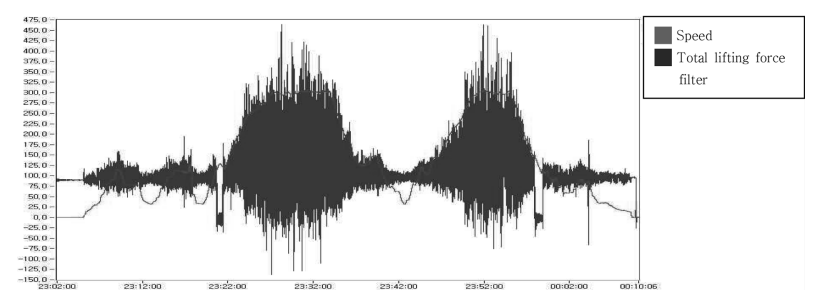

Fig. 15 Test data

\section{Conclusion}

This study assessed pantograph contact forces in KTX-II (Sancheon) duplicate operation in cooperation with the Korea Railway Research Institute to measure contact force and loss of contact rate by elevating speed in a phased manner. The resulting power collection was also evaluated for its quality. During the test, the researchers adjusted upward the angles of Air poil and the direction of Air spoiler attached on pantographs to find the optimal contact force through diverse methods. Studies on catenary system, pantograph wave, contact forces, etc. related to duplicate operation are still in their initial stage in South Korea. And pantographs should be further developed for better customization to satisfy the country's specific needs for catenary. In this situation, the researchers believe there should be more studies on how to improve the interface with catenary in duplicate operation.

\section{References}

1. Multiple Pantograph Interaction with Catenaries in HighSpeed Trains - Technical University of Lisbon, Lisbon, Portugal;SNCF, 75008 Paris, France.

2. KTX-II Duples Pantograph Test Report, Korea Railway Research institute, July 16, 2010.

3. Plan for the Main Line Test Run of the High-Speed Train Technology Development Project; by Cho, Yong-hyun, et al.; Korea Railway Research institute, 2002.

4. Study on Dynamic Characteristic Measurement by Using Sensors and Optic Devices; doctorate thesis by Kim, InChol; 2009. 